\title{
ANALISIS KEPUASAN KONSUMEN DI RESTORAN SEDERHANA PADANG DENGAN MENGGUNAKAN ANALISIS FAKTOR
}

\author{
DEBY CINTYA RIZAL, MAIYASTRI* YUDIANTRI ASDI \\ Program Studi S1 Matematika, \\ Fakultas Matematika dan Ilmu Pengetahuan Alam, Universitas Andalas, \\ Kampus UNAND Limau Manis Padang, Indonesia \\ email : debycintyarizaal@gmail.com, maiyastri@sci.unand.ac.id,yudiantriasdi@sci.unand.ac.id
}

Diterima 4 Agustus 2021 Direvisi 15 September $2021 \quad$ Dipublikasikan 21 Oktober 2021

\begin{abstract}
Abstrak. Analisis faktor adalah teknik analisis multivariat yang digunakan untuk mengelompokkan variabel-variabel yang berkorelasi ke dalam kelompok variabel yang disebut faktor dimana antara satu faktor dengan faktor lainnya tidak saling berkorelasi. Faktor-faktor yang terbentuk ini dapat menerangkan sebagian besar informasi yang terkandung pada variabel. Pada penelitian ini dilakukan analisis faktor untuk menentukan faktor-faktor kepuasan konsumen di Restoran Sederhana Padang. Analisis yang digunakan adalah analisis faktor eksploratori dengan metode pendugaan Principal Component Analysis (PCA). Metode rotasi faktor yang digunakan adalah rotasi varimax. Data yang digunakan merupakan data primer yang diperoleh melalui penyebaran kuesioner kepada seratus orang konsumen Restoran Sederhana Padang. Dari penelitian ini diperoleh bahwa terdapat tiga faktor yang menjadi faktor-faktor kepuasan konsumen Restoran Sederhana Padang. Ketiga faktor tersebut yaitu faktor produk dan pelayanan, faktor harga produk, dan faktor emosional konsumen.

Kata Kunci: Analisis faktor, Kepuasan Konsumen, Principal Component Analysis $(\mathrm{PCA})$
\end{abstract}

\section{Pendahuluan}

Sektor industri merupakan salah satu sektor penunjang berhasilnya pembangunan ekonomi suatu negara, termasuk di Indonesia. Keuntungan yang diperoleh membuat kalangan pebisnis berlomba-lomba untuk membangun bidang usaha dengan tujuan mendapatkan keuntungan yang tentunya juga akan berdampak pada pembangunan ekonomi negara. Di Indonesia sendiri sampai saat ini masih mengandalkan sektor industri makanan dan minuman karena dinilai mampu memberikan kontribusi yang besar terhadap perekonomian nasional [4]. Di Sumatera Barat, khususnya Kota Padang terdapat 4000 industri kecil menengah di bidang makanan di Kota Padang [1]. Salah satunya adalah Restoran Sederhana Padang.

*penulis korespondensi 
Restoran Sederhana Padang telah berdiri sejak tahun 2008 dan sampai saat ini masih menjadi tujuan wisata kuliner utama di Kota Padang. Persaingan di dunia usaha kuliner membuat Restoran Sederhana memikirkan cara untuk membuat konsumennya merasa puas dan kembali lagi membeli produk yang ditawarkan. Demi memenangkan persaingan bisnis dengan memberikan kepuasan kepada para konsumennya, maka Restoran Sederhana Padang perlu mengetahui faktor-faktor apa saja yang mempengaruhi kepuasan konsumen sehingga nantinya bisa mengatur strategi penjualan agar konsumen merasa puas dan tetap kembali ke Restoran Sederhana Padang.

Pada penelitian ini digunakan analisis faktor eksploratori untuk menganalisis kepuasan konsumen Restoran Sederhana Padang. Analisis Faktor Eksploratori (AFE), selanjutnya disebut analisis faktor, digunakan untuk mengumpulkan variabel-variabel yang saling berkorelasi ke dalam kelompok-kelompok variabel. Kelompok variabel yang terbentuk tersebut disebut dengan faktor, di mana antara satu faktor dengan faktor lainnya tidak berkorelasi. Faktor-faktor yang terbentuk tersebut dapat menjelaskan sebagian besar informasi yang terkandung pada variabel $[2]$.

\section{Analisis Faktor}

Analisis Faktor merupakan analisis yang digunakan untuk mengumpulkan variabelvariabel yang saling berkorelasi ke dalam kelompok-kelompok variabel. Kelompok variabel yang terbentuk tersebut disebut dengan faktor, di mana antara satu faktor dengan faktor lainnya tidak berkorelasi. Faktor-faktor yang terbentuk tersebut dapat menjelaskan sebagian besar informasi yang terkandung pada variabel [2].

\subsection{Matriks Korelasi Antar Variabel}

Matriks korelasi merupakan matriks yang dibentuk untuk mendapatkan nilai kedekatan hubungan diantara variabel-variabel yang digunakan dalam analisis. Nilai korelasi dapat diperoleh dengan korelasi Pearson berikut ini [5].

$$
r_{x y}=\frac{n \sum_{i=1}^{n} X_{i} Y_{i}-\left(\sum_{i=1}^{n} X_{i}\right)\left(\sum_{i=1}^{n} Y_{i}\right)}{\sqrt{n \sum_{i=1}^{n} X_{i}^{2}-\left(\sum_{i=1}^{n} X_{i}\right)^{2}} \sqrt{n \sum_{i=1}^{n} Y_{i}^{2}-\left(\sum_{i=1}^{n} Y_{i}\right)^{2}}}
$$

\subsection{Uji Asumsi Analisis Faktor}

Pada analisis faktor dibutuhkan variabel-variabel yang memiliki korelasi kuat untuk dapat masuk ke dalam suatu faktor. Untuk mengidentifikasi hubungan diantara variabel-variabel yang digunakan pada penelitian ini, akan dilakukan uji-uji asumsi analisis faktor sebagai berikut:

(1) Uji Kaiser Meyer Olkin (KMO)

Uji ini bertujuan untuk mengetahui kelayakan data apabila dilakukan analisis dengan menggunakan analisis faktor [6]. Nilai KMO dapat dihitung dengan persamaan berikut. 


$$
K M O=\frac{\sum_{i}^{p} \sum_{j \neq i}^{p} r_{i j}^{2}}{\sum_{i}^{p} \sum_{j \neq i}^{p} r_{i j}^{2}+\sum_{i}^{p} \sum_{j \neq i}^{p} a_{i j}^{2}}
$$

$r_{i j}^{2}$ adalah koefisien korelasi dari variabel $i$ dan $j, a_{i j}^{2}$ adalah koefisien korelasi parsial dari variabel $i$ dan $j$, untuk $i=1,2, \cdots, p$ dan $j=1,2, \cdots, p$. Data penelitian dikatakan layak untuk dilakukan analisis dengan analisis faktor apabila memiliki nilai $\mathrm{KMO}>0,50$.

(2) Uji Bartlett

Uji ini bertujuan untuk mengetahui hubungan atau korelasi diantara variabel-variabel yang digunakan. Hipotesis pada uji Bartlett sebagai berikut [5]:

(a) $H_{0}$ : tidak terdapat korelasi antarvariabel

$H_{1}$ : terdapat korelasi antarvariabel

(b) Taraf signifikansi $\alpha=0,05$

(c) Statistik uji yang digunakan

$$
\chi_{\text {hit }}^{2}=-\left(n-1-\frac{2 p+5}{6}\right) \ln |R|
$$

$n$ adalah banyak sampel, $p$ adalah banyak variabel, dan $|R|$ adalah determinan matriks korelasi.

(d) Keputusan dapat diperoleh dengan

i. Tolak $H_{0}$ jika nilai $\chi_{h i t}^{2}>\chi_{\alpha, \frac{p(p-1)}{2}}^{2}$. Tidak tolak $H_{0}$ jika nilai $\chi_{h i t}^{2} \leq$ $\chi_{\alpha, \frac{p(p-1)}{2}}^{2}$, atau

ii. Tolak $H_{0}$ jika $p$-value $<\alpha$. Tidak tolak $H_{0}$ jika $p$-value $\geq \alpha$

(3) Uji Measure of Sampling Adequacy (MSA)

Uji ini bertujuan untuk mengetahui kelayakan variabel untuk dilakukan analisis dengan analisis faktor [6]. Nilai MSA dapat dihitung dengan persamaan berikut

$$
M S A=\frac{\sum_{i}^{p} \sum_{j \neq i}^{p} r_{i j}^{2}}{\sum_{i}^{p} \sum_{j \neq i}^{p} a_{i j}^{2}}
$$

$r_{i j}^{2}$ adalah koefisien korelasi dari variabel $i$ dan $j, a_{i j}^{2}$ adalah koefisien korelasi parsial dari variabel $i$ dan $j$, untuk $i=1,2, \cdots, p$ dan $j=1,2, \cdots, p$. Variabel dikatakan layak untuk dilakukan analisis dengan analisis faktor apabila memiliki nilai $\mathrm{MSA}>0,50$.

\subsection{Model Analisis Faktor}

Misalkan peubah acak teramati $X$ dengan $p$ komponen memiliki rata-rata $\mu$ dan matriks varian kovarian $\Sigma$. Pada model faktor, $X$ merupakan kombinasi linear dari beberapa peubah acak yang tidak teramati $F_{1}, F_{2}, \cdots, F_{m}$ yang disebut common factor (faktor bersama), dan $\varepsilon_{1}, \varepsilon_{2}, \cdots, \varepsilon_{p}$ yang disebut kesalahan (error) atau faktor spesifik [6]. Model dari analisis faktor sebagai berikut [3]. 


$$
\begin{gathered}
X_{1}-\mu_{1}=l_{11} F_{1}+l_{12} F_{2}+\cdots+l_{1 m} F_{m}+\varepsilon_{1} \\
X_{2}-\mu_{2}=l_{21} F_{1}+l_{22} F_{2}+\cdots+l_{2 m} F_{m}+\varepsilon_{2} \\
\vdots \\
X_{p}-\mu_{p}=l_{p 1} F_{1}+l_{p 2} F_{2}+\cdots+l_{p m} F_{m}+\varepsilon_{p}
\end{gathered}
$$

Model analisis faktor tersebut dapat dinyatakan dalam bentuk matriks sebagai berikut.

$$
\boldsymbol{X}_{(p x 1)}-\boldsymbol{\mu}_{(p x 1)}=\boldsymbol{L}_{(p x m)} \boldsymbol{F}_{(m x 1)}+\boldsymbol{\varepsilon}_{(p x 1)}
$$

$p$ adalah banyaknya variabel yang dianalisis, $m$ adalah jumlah faktor yang terbentuk, dan $l_{i j}$ adalah factor loading dari peubah ke- $i$ pada faktor ke- $j$.

Proporsi ragam dari variabel ke- $i$ yang diterangkan oleh $m$ faktor bersama disebut dengan komunalitas ke- $i$ dinotasikan sebagai $h_{i}^{2}$. Proporsi ragam dari variabel ke- $i$ yang disebabkan oleh faktor spesifik disebut ragam spesifik dinotasikan dengan $\psi_{i}[2]$. Nilai $\operatorname{Var}\left(\boldsymbol{X}_{\boldsymbol{i}}\right)=\Sigma_{i i}$ merupakan nilai komunalitas yang ditambahkan dengan nilai faktor spesifiknya sehingga diperoleh

$$
\operatorname{Var}\left(\boldsymbol{X}_{\boldsymbol{i}}\right)=\Sigma_{i i}=l_{i 1}^{2}+l_{i 2}^{2}+\cdots+l_{i m}^{2}+\psi_{i}=h_{i}^{2}+\psi_{i}
$$

dengan

$$
h_{i}^{2}=l_{i 1}^{2}+l_{i 2}^{2}+\cdots+l_{i m}^{2} \text { untuk } i=1,2, \cdots, p .
$$

\subsection{Ekstraksi Faktor}

Dalam ekstrasi faktor ada dua metode yang digunakan, yaitu Common Factor Analysis (CFA) dan Component Analysis. Component Analysis atau dikenal juga dengan Principal Component Analysis (PCA) digunakan untuk mereduksi sejumlah variabel menjadi kelompok variabel (faktor) yang mampu menjelaskan informasi (keragaman) variabel. PCA juga digunakan untuk melakukan transformasi variabel yang saling berkorelasi menjadi kelompok variabel yang tidak berkorelasi. Penentuan jumlah faktor apabila ekstraksi faktor dilakukan dengan metode PCA adalah dengan menggunakan kriteria nilai eigen. Nilai eigen merupakan jumlah varian yang dijelaskan oleh setiap faktor. Dengan PCA setiap variabel memberikan kontribusi nilai 1 terhadap total nilai eigen. Jadi hanya faktor yang memiliki nilai eigen $>1$ yang dianggap signifikan [2].

\subsection{Rotasi Faktor}

Dalam analisis faktor, rotasi faktor dilakukan untuk mempermudah dalam menginterpretasikan faktor. Rotasi faktor dilakukan dengan merotasikan factor loading. Factor loading adalah nilai korelasi dari setiap variabel dan faktor. Dalam rotasi faktor, ada dua metode rotasi yang digunakan, yaitu metode rotasi oblique dan metode rotasi ortogonal. Pada metode rotasi oblique, sumbu faktor saling membentuk sudut dengan besar sudut tertentu dan memungkinkan faktor berkorelasi. Ada empat metode dalam rotasi oblique, yaitu oblimin, quartimin, biquartimin, 
dan covarimin. Sedangkan pada metode rotasi ortogonal, rotasi dilakukan dengan mempertahankan sumbu faktor pada sudut $90^{\circ}$ atau sumbunya saling tegak lurus. Hal ini membuat setiap faktor saling bebas (tidak berkorelasi) dengan faktor yang lain karena sumbu antar faktor saling tegak lurus. Ada tiga metode dalam rotasi ortogonal, yaitu quartimax, varimax, dan equimax. Metode rotasi varimax menghasilkan beberapa nilai factor loading yang tinggi dan beberapa nilai factor loading mendekati 0. Artinya, dengan menggunakan metode varimax akan didapatkan factor loading yang tinggi hanya pada satu faktor saja, sedangkan factor loading yang lainnya mendekati 0 [2].

\subsection{Interpretasi Faktor}

Interpretasi hasil analisis faktor dapat dilakukan dengan langkah-langkah berikut ini:

(1) Memeriksa matriks factor loading.1

(2) Identifikasi factor loading yang signifikan pada setiap variabel.1

(3) Memeriksa komunalitas masing-masing variabel.

Komunalitas adalah proporsi ragam dari variabel yang dapat dijelaskan oleh faktor yang terbentuk. Nilai komunalitas $<0,50$ dianggap tidak penting atau tidak memiliki penjelasan yang cukup sehingga variabel dengan nilai komunalitas $<0,50$ dikeluarkan dari analisis, lalu dilakukan analisis faktor ulang [2].

(4) Mengklasifikasikan lagi model faktor jika dibutuhkan.

(5) Penamaan faktor.

\section{Metode Penelitian}

Data yang digunakan dalam penelitian ini adalah data primer yang diperoleh dengan menyebarkan kuesioner kepada konsumen Restoran Sederhana Padang. Pada kuesioner yang disebarkan kepada responden, peneliti menggunakan skala likert. Teknik pengambilan sampel yang digunakan adalah snowball sampling. Sampel yang digunakan sebanyak 100 sampel. Penyebaran kuesioner dilakukan pada tanggal 19 Februari 2021 - 9 Maret 2021.

Variabel yang digunakan pada penelitian ini adalah variabel-variabel indikator yang diperoleh dari literatur, yaitu: produk memiliki rasa yang enak $\left(X_{1}\right)$, produk tidak mudah basi $\left(X_{2}\right)$, produk dalam kondisi segar $\left(X_{3}\right)$, kualitas bahan baku baik $\left(X_{4}\right)$, tersedianya alat bantu makan dan minum $\left(X_{5}\right)$, tampilan produk menarik $\left(X_{6}\right)$, harga yang ditawarkan terjangkau oleh konsumen $\left(X_{7}\right)$, harga sesuai dengan kualitas produk $\left(X_{8}\right)$, harga yang ditawarkan masuk akal $\left(X_{9}\right)$, harga yang ditawarkan tidak jauh beda dengan pesaing $\left(X_{10}\right)$, fasilitas fisik dan karyawan $\left(X_{11}\right)$, karyawan tepat dan akurat $\left(X_{12}\right)$, karyawan memberikan pelayanan dengan cepat $\left(X_{13}\right)$, keramahan dan kemampuan karyawan $\left(X_{14}\right)$, karyawan memperhatikan kebutuhan konsumen $\left(X_{15}\right)$, adanya rasa bangga menjadi konsumen $\left(X_{16}\right)$, adanya perasaan yakin akan kekaguman orang lain $\left(X_{17}\right)$, konsumen merasa mudah dan nyaman dalam memperoleh produk $\left(X_{18}\right)$. 


\section{Hasil dan Pembahasan}

Setelah dilakukan analisis faktor secara berulang, ditemukan bahwa nilai komunalitas pada variabel $X_{1}, X_{2}, X_{5}$ dan $X_{11}<0,50$ sehingga akan dilakukan analisis faktor ulang dengan tidak melibatkan variabel-variabel tersebut.

(1) Matriks Korelasi Antar Variabel.

Semua variabel yang digunakan pada penelitian ini saling berkorelasi antara satu dengan yang lainnya. Salah satunya nilai koefisien korelasi dari variabel $X_{7}$ (harga yang ditawarkan terjangkau oleh konsumen) dan $X_{9}$ (harga yang ditawarkan masuk akal) yaitu sebesar 0,854 .

(2) Uji Asumsi.

Setelah dilakukan analisis faktor diperoleh nilai KMO > 0,50 yaitu sebesar 0,881 yang berarti bahwa data baik untuk dianalisis dengan analisis faktor. Oleh karena itu, metode analisis faktor dapat digunakan untuk menganalisis faktor-faktor kepuasan konsumen Restoran Sederhana dan proses analisis faktor dapat dilanjutkan. Kemudian diperoleh nilai uji Bartlett $<0,05$ yaitu sebesar 0,000 yang berarti bahwa variabel-variabel yang digunakan pada penelitian ini saling berkorelasi. Serta semua variabel pada penelitian ini memiliki nilai MSA $>0,50$ yang berarti bahwa semua variabel tersebut sudah layak untuk dianalisis dengan analisis faktor.

(3) Ekstraksi Faktor.

Dengan menggunakan Principal Component Analysis (PCA) diperoleh hasil bahwa terdapat tiga faktor yang memiliki nilai eigen $>1$. Artinya, setelah melakukan ekstraksi terbentuk tiga faktor yang menjadi faktor-faktor kepuasan konsumen Restoran Sederhana Padang. Proporsi keragaman kumulatif dari tiga faktor yang terbentuk sebesar 74,993\%. Selain itu, diperoleh juga bahwa seluruh variabel pada penelitian ini memiliki nilai komunalitas $>0,50$.

(4) Rotasi Faktor.

Setelah dilakukan rotasi faktor varimax, diperoleh bahwa nilai factor loading tinggi hanya pada salah satu faktor saja. Pada penelitian ini nilai factor loading signifikan apabila nilainya $>0,55$. Namun pada variabel $X_{18}$ nilai factor loadingnya $<0,55$ sehingga variabel $X_{18}$ tidak diikutsertakan dalam interpretasi.

(5) Interpretasi Faktor.

Faktor-faktor yang terbentuk pada penelitian ini adalah sebagai berikut:

(a) Faktor Produk dan Pelayanan. Terdiri dari: $X_{6}, X_{12}, X_{13}, X_{3}, X_{15}, X_{4}, X_{14}$ dengan masing-masing factor loading secara berturut-turut sebesar 0,828 ; 0,$822 ; 0,783 ; 0,774 ; 0,711 ; 0,689 ; 0,679$.

(b) Faktor Harga Produk. Terdiri dari: $X_{7}, X_{9}, X_{8}, X_{10}$ dengan masing-masing factor loading secara berturut-turut sebesar 0,$872 ; 0,871 ; 0,776 ; 0,734$.

(c) Faktor Emosional Konsumen. Terdiri dari: $X_{17}$ dan $X_{16}$ dengan masingmasing factor loading secara berturut-turut sebesar 0,897 dan 0,811. 


\section{Kesimpulan}

Berdasarkan hasil analisis dengan menggunakan metode analisis faktor, dari 18 variabel indikator yang digunakan pada penelitian ini diperoleh tiga faktor yang menjadi faktor-faktor kepuasan konsumen Restoran Sederhana Padang, yaitu: Faktor Produk dan Pelayanan, semua variabel pada faktor ini memiliki nilai factor loading di atas 0,60 dengan nilai tertinggi pada $X_{6}$ (tampilan produk menarik) sebesar 0,828 juga mampu menjelaskan keragaman sebesar 56,587\%. Faktor Harga Produk, semua variabel pada faktor ini memiliki nilai factor loading di atas 0,70 dengan nilai tertinggi pada $X_{7}$ (harga yang ditawarkan terjangkau oleh konsumen) sebesar 0,872 juga mampu menjelaskan keragaman sebesar 10,419\%. Faktor Emosional Konsumen, semua variabel pada faktor ini memiliki nilai factor loading di atas 0,80 dengan nilai tertinggi pada $X_{17}$ (adanya perasaan yakin akan kekaguman orang lain) sebesar 0,897 juga mampu menjelaskan keragaman sebesar 7,987\%. Proporsi keragaman kumulatif dari ketiga faktor yang terbentuk tersebut sebesar 74,993\%.

\section{Ucapan Terima kasih}

Penulis mengucapkan terimakasih kepada ibu Ferra Yanuar, bapak Budi Rudianto, dan ibu Nova Noliza Bakar yang telah memberikan masukan dan saran sehingga artikel ini dapat diselesaikan dengan baik.

\section{Daftar Pustaka}

[1] Dinas Tenaga Kerja dan Perindustrian Kota Padang. 2017. Ikm padang didominasi oleh industri makanan. https://disnakerin.padang.go.id/index. php/beritaterkini2/299-ikm-padang-didominasi-oleh-industri-makanan,

[2] Hair JR, J.F., W.C. Black, B.J. Babin, R.E. Anderson. 2014. Multivariate Data Analysis. Seventh Edition. London, Pearson Education Limited

[3] Jhonson, R.A. dan D.W. Wichern. 2007. Applied Multivariate Statistical Analysis. Sixth Edition. New Jersey, Pearson Education Inc

[4] Kementerian Perindustrian Republik Indonesia. 2017. Industri makanan dan minuman masih jadi andalan. https://kemenperin.go.id/ artikel/18465/Industri-Makanan-dan-Minuman-Masih-Jadi-Andalan,

[5] Putri, R.A. 2017. Penentuan Indikator Kesehatan Bayi dengan Menggunakan Analisis Faktor. Skripsi Sarjana. tidak diterbitkan. Universitas Andalas, Padang

[6] Usman, H. dan N. Sobari. 2013. Aplikasi Teknik Multivariate: Untuk Riset Pemasaran. Jakarta, Raja Grafindo Persada 